\title{
Pre-consultation educational group intervention to improve shared decision-making in postmastectomy breast reconstruction: study protocol for a pilot randomized controlled trial
}

Jennica Platt, Nancy Baxter, Jennifer Jones, Kelly Metcalfe, Natalie Causarano, Stefan OP Hofer, Anne O’Neill, Terry Cheng, Elizabeth Starenkyj and Toni Zhong*

\begin{abstract}
Background: The Pre-Consultation Educational Group Intervention pilot study seeks to assess the feasibility and inform the optimal design for a definitive randomized controlled trial that aims to improve the quality of decisionmaking in postmastectomy breast reconstruction patients.

Methods/design: This is a mixed-methods pilot feasibility randomized controlled trial that will follow a singlecenter, 1:1 allocation, two-arm parallel group superiority design.

Setting: The University Health Network, a tertiary care cancer center in Toronto, Canada.

Participants: Adult women referred to one of three plastic and reconstructive surgeons for delayed breast reconstruction or prophylactic mastectomy with immediate breast reconstruction.

Intervention: We designed a multi-disciplinary educational group workshop that incorporates the key components of shared decision-making, decision-support, and psychosocial support for cancer survivors prior to the initial surgical consult. The intervention consists of didactic lectures by a plastic surgeon and nurse specialist on breast reconstruction choices, pre- and postoperative care; a value-clarification exercise led by a social worker; and discussions with a breast reconstruction patient.

Control: Usual care includes access to an informational booklet, website, and patient volunteer if desired. Outcomes: Expected pilot outcomes include feasibility, recruitment, and retention targets. Acceptability of intervention and full trial outcomes will be established through qualitative interviews. Trial outcomes will include decision-quality measures, patient-reported outcomes, and service outcomes, and the treatment effect estimate and variability will be used to inform the sample size calculation for a full trial.

Discussion: Our pilot study seeks to identify the (1) feasibility, acceptability, and design of a definitive RCT and (2) the optimal content and delivery of our proposed educational group intervention. Thirty patients have been recruited to date (8 April 2013), of whom 15 have been randomized to one of three decision support workshops. The trial will close as planned in May 2013.

Trial registration: NCT01857882
\end{abstract}

\footnotetext{
* Correspondence: toni.zhong@uhn.ca

UHN Breast Restoration Program, Division of Plastic and Reconstructive

Surgery, 8N 871, 200 Elizabeth Street, Toronto, ON M5G 2C4, Canada
} 


\section{Background}

Women with a history of breast cancer now constitute the largest group of cancer survivors [1], with over $85 \%$ surviving for greater than 5 years after diagnosis [2]. Mastectomy remains a common form of breast cancer treatment, with $37 \%$ of American women undergoing mastectomy as their definitive cancer treatment in 2006 [3]. The goal of breast reconstruction is to reconstruct a mastectomy defect without affecting cancer outcomes [4]. The opportunity to restore the breast mound through reconstructive surgery has been shown to enhance a woman's self-image and femininity [5-7], as well as provide psychosocial benefit [8].

The majority of women who undergo breast reconstruction are satisfied with the outcome and the aesthetic result [5,9-11]. However, one fourth of women report being dissatisfied with some component of their cancer or reconstructive care [12]. Failure of the physician to provide adequate information about treatment options is the most frequent source of cancer patient dissatisfaction [13], and breast reconstruction patients have expressed a need for further information regarding the complex decision to pursue breast reconstruction [14-16]. Information dissatisfaction and a mismatch between a patients' preferred and actual role in decisionmaking may contribute to decision regret in breast oncology patients [12,17-19]. Implementation of strategies to incorporate shared decision-making can improve the quality of treatment decisions [20]. Developing the self-confidence to make and express a treatment decision (defined as decision self-efficacy [21]) is a necessary component of shared-decision making, and this attribute can be enhanced through decision support interventions [22].

Given the financial and time constraints that exist in our current health-care system, it is not feasible to relay detailed information regarding every aspect of breast reconstruction during a single patient consultation. In addition, the breast reconstruction discussions can be highly complex, as there are many different techniques (implant vs. autologous tissue, one-stage vs. two-stage), timing (delayed vs. immediate), and complications that are unique to each procedure $[4,23]$. In such scenarios of complex medical decision-making, decision support techniques may be an effective solution to information provision [13] and shared decision-making [14,24]. As a result, we developed a pre-consultation educational group intervention delivered in a group setting for women considering breast reconstruction, with the aims to fill an existing information-gap, promote high-quality decision-making, and enhance decision self-efficacy. This pilot study will be the first step in the evaluation of our educational group intervention, and the results will be used to determine the feasibility and inform the optimal design for a definitive randomized controlled trial.
Figure 1 shows a pre- and postoperative photo of a patient who underwent delayed breast reconstruction using autologous tissue reconstruction.

\section{Hypothesis}

Patients seeking consultation for breast reconstruction allocated to the pre-consultation educational group intervention plus usual care will have greater decision self-efficacy, satisfaction with information, decision preference, and decision choice, perceived involvement in care, breast reconstruction knowledge, and less decisional conflict as measured approximately 1 week after intervention and surgical consultation compared with patients allocated to receive usual care alone.

\section{Pilot study objectives}

1. To determine feasibility and acceptability of randomization, intervention uptake, and data collection

2. To assess implementation and fidelity of the outcome measures and intervention

3. To pilot trial procedures including recruitment (giving information and obtaining preliminary consent via telephone recruitment), randomization, intervention delivery (workshop scheduled same day as initial surgical consult), and outcome measurement (mailed questionnaires)

4. To use qualitative research methods to assess the content and acceptability of the intervention and learn from patient interviews how to improve the delivery of the intervention for the full trial

5. To obtain estimates of variance and a preliminary estimate of the effect of the intervention on preliminary trial outcomes (decision self-efficacy, satisfaction with information, decision preference and decision choice, decisional conflict) and service outcomes such as duration of consultation.

\section{Methods/design}

This is a mixed-methods pilot feasibility randomized controlled trial that will follow a single-center, 1:1 allocation, two-arm parallel group superiority design. The study setting will be the University Health Network (UHN), a tertiary care cancer center in Toronto, Canada, with three plastic and reconstructive surgeons who specialize in breast reconstruction. Research ethics board approval was obtained from the University Health Network (11-1027-CE).

\section{Participants}

Adult women referred to one of the plastic surgeons for consideration of breast reconstruction will be eligible to participate. The study coordinator is responsible for identification and recruitment of potentially eligible 

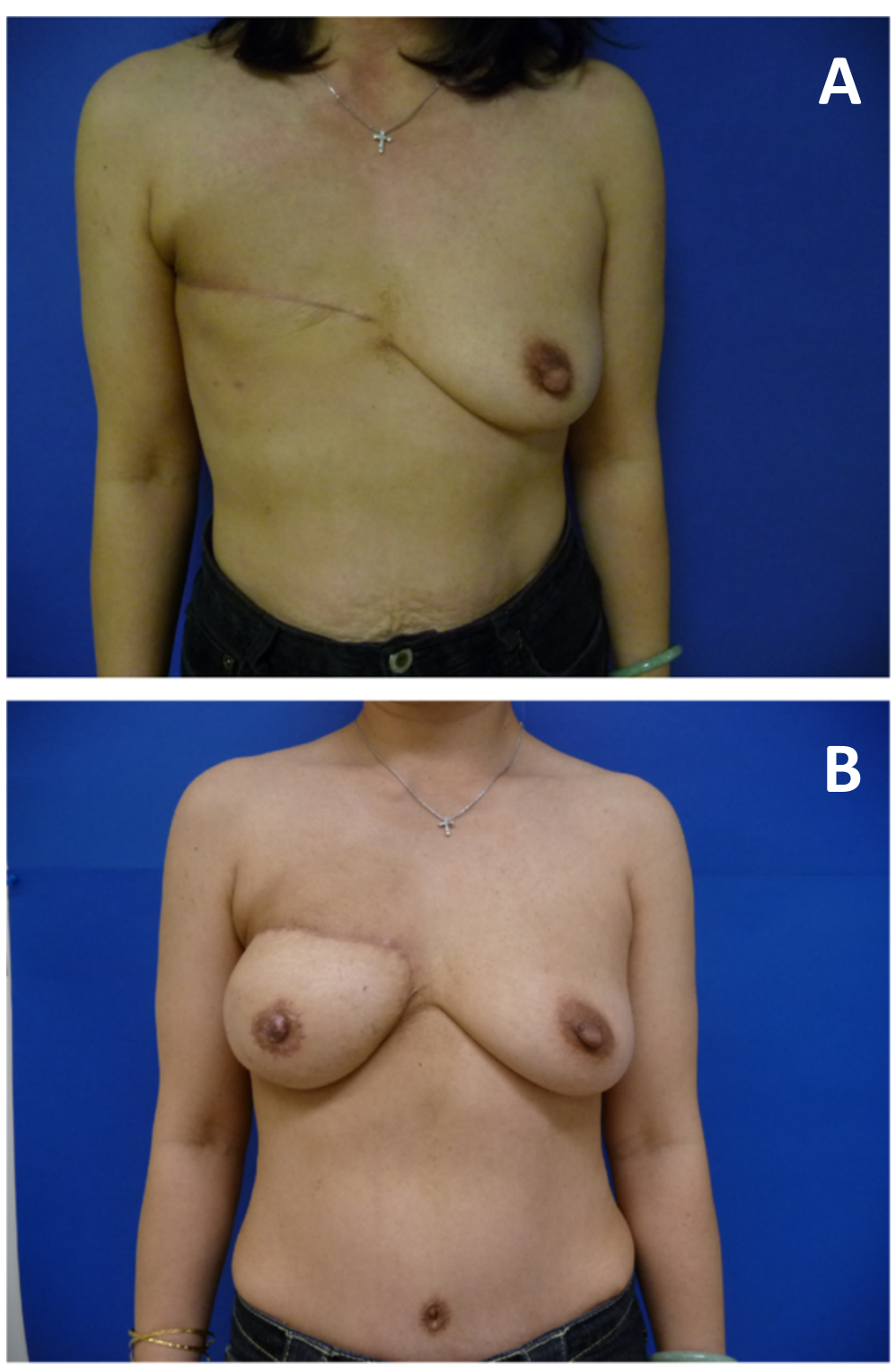

Figure 1 Delayed breast reconstruction. (A) Preoperative photograph demonstrating right mastectomy defect after post-mastectomy radiation. (B) Postoperative photograph after delayed breast reconstruction using autologous tissue reconstruction.

participants. Because the intervention (educational workshop) will occur before the initial surgical consultation, it is necessary to identify subjects from faxed referrals and determine their eligibility via telephone confirmation at the time of recruitment and prior to the initial surgical consultation. Participants will be excluded if they are referred for reconstruction after atypical breast malignancy (e.g., angiosarcoma) or metastatic breast cancer, secondary breast reconstruction, have cognitive impairment or uncontrolled psychiatric diagnosis, or cannot read or write in English. Once eligibility has been confirmed with the study coordinator, subjects who indicate an interest in participation will be enrolled after providing informed consent over the telephone, and study packages will subsequently be mailed. Participants will be officially registered upon receipt of signed consent through return mail. Baseline measures (T0) will be assessed prior to randomization and returned in postage-paid envelopes. Participants in the study and control groups will complete $\mathrm{T} 1$ measures approximately 1 week after the initial surgical consultation. The participant timeline is outlined in Figure 2.

\section{Randomization and allocation of interventions}

Once informed consent has been obtained from each participant and the baseline questionnaire returned by 

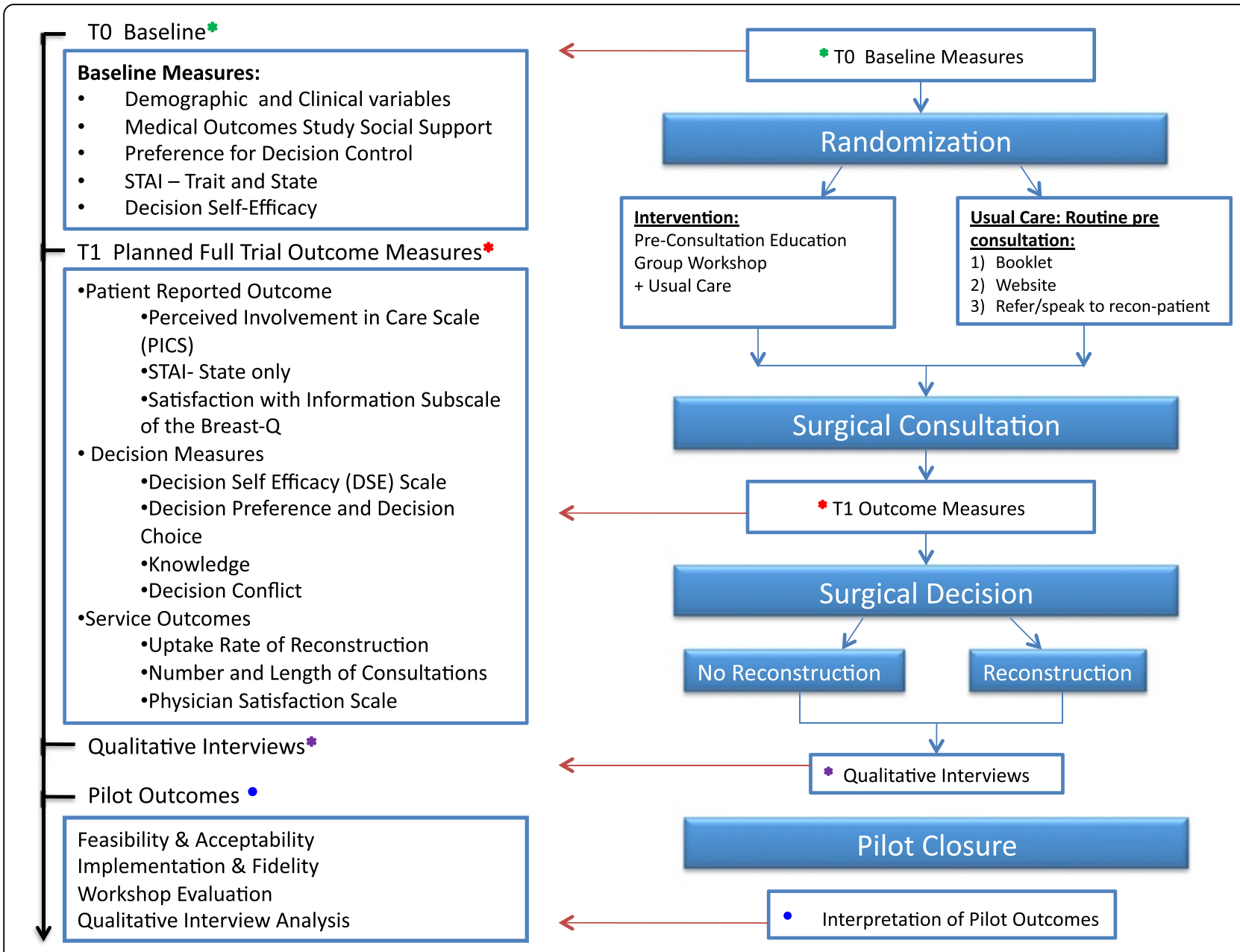

Figure 2 Study design flowchart and participant timeline.

mail, the next opaque, sealed envelope in sequence will be opened by the study coordinator to determine the participant's randomized treatment allocation. A computergenerated random allocation sequence will be created and sealed in opaque envelopes by the program biostatistician independent form the study coordinator with 1:1 allocation to the educational group intervention or usual care and balanced in blocks of ten.

\section{Intervention}

Patients in the experimental group will participate in a pre-consultation educational group intervention in addition to receiving usual care. The intervention will be $2 \mathrm{~h}$ in duration on the morning of the consultation and will be facilitated by a dedicated social worker from psycho-oncology. Concerning the workshop development and structure, the intervention will incorporate the key components of shared decision-making (patientphysician involvement, shared information, expression of preferences) [13] and decision support (information provision, values clarification and patient involvement) [25-27] with the philosophy of delivering supportive care to cancer patients [28-30].

- Surgeon - 30 min: treatment options for breast reconstruction with indications/contraindications, advantages/disadvantages, expected postoperative course, aesthetic result (realistic photos), and complications with probabilities

- Registered nurse - 30 min: preparing for surgery, postoperative recovery, and how to navigate the health-care system

- Social worker $(\mathrm{SW})$ - 30 min: values clarification exercise (Figure 3)

- Breast reconstruction patient volunteer: $30 \mathrm{~min}$ : questions and answers about her personal experience

Patients in the experimental and control group will receive usual care. At the UHN, all patients are asked to 


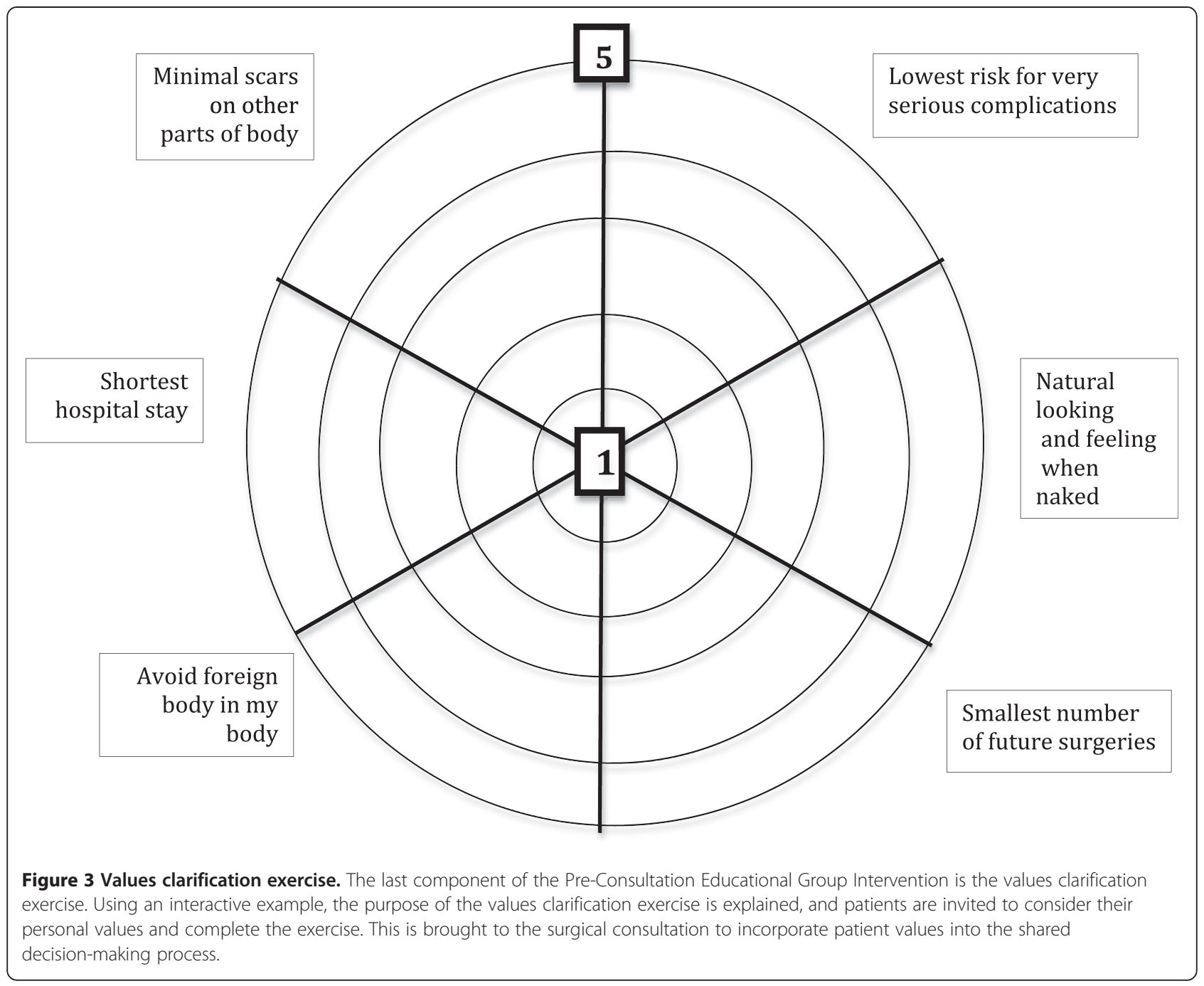

read a breast reconstruction information booklet and visit the website developed by the group prior to their consultation with the plastic surgeons. They are then booked for a 45-min consultation with a consultant plastic surgeon and a surgical resident or fellow. A thorough history and physical exam are performed, and specific information regarding reconstruction options, advantages, and complications is provided, followed by a discussion about patient preferences. In addition, all patients are referred to speak with a volunteer patient at a later date if desired. Appointments will be scheduled in batches to prevent contamination between those randomized to the experimental and control groups.

\section{Outcome measures}

\section{Pilot and feasibility outcome measures}

Feasibility and acceptability of randomization, treatment allocation, and data-collection procedures: Recruitment and attrition rates will be recorded. We will measure the proportion of participants that submits complete primary and secondary outcome measures and baseline questionnaires. Treatment Implementation and fidelity: We will record the proportion of participants who received their randomly allocated treatment assignment to monitor participant adherence to treatment allocation. Acceptability of interventions, assessment of primary outcome, and refinement of the educational group intervention content and delivery: A subgroup of participants allocated to both the experimental and usual care groups will be asked to participate in a brief qualitative telephone interview. Purposeful sampling will be used to recruit five patients from each group to achieve data saturation and variability [31]. Telephone interviews will be conducted by a social worker trained in qualitative methods after the decision regarding breast reconstruction has been made, which we consider to be when a patient signs the surgical consent. All participants randomized to the workshop will additionally be asked 
to complete a written survey for evaluation of the intervention immediately after participation in the workshop.

\section{Trial outcome measures will be divided into three broad categories}

Decision measures will include decision self-efficacy [21], decision conflict score [32], decision preference, and decision choice [33]. These three instruments will be given at T0 (baseline) and T1, after the surgical consultation with the plastic surgeon.

1) The decision self-efficacy (DSE) scale is a prospectively designed instrument to evaluate patient self-confidence in decision-making, including shared decision-making [21]. It has been validated among women facing treatment decisions for osteoporosis [21] and used in cancer patients [22]. Psychometric evaluation has shown high levels of internal consistency (Cronbach's alpha 0.90). Decision self-efficacy is correlated with decision conflict subscales of feeling informed $(r=0.47)$ and supported $(r=0.45)$ [21]. This instrument has never been tested in the breast cancer or breast reconstruction population.

2) The decision conflict scale measures personal perceptions of uncertainty in choosing options and has been demonstrated to be valid and responsive to change [32]. The decisional conflict scale is a 16-item 5-response instrument that reports a score from 0 - 100 with higher scores indicating more conflict (items are summed, divided by 16 and multiplied by 25) $[26,34]$.

3) Decision Preference and Decision Choice has been used as a primary and secondary outcome in studies of decision support interventions in cancer patients. It demonstrates good test-retest reliability (test-retest coefficient $>0.90$ ) and is sensitive to change when measured before and after an intervention [33].

Patient reported outcomes (PRO) will be measured using the perceived involvement in care scale [35] (PICS) and satisfaction with information subscale of BREAST-Q [36-39].

1) PICS is a measure of patient perception of involvement with her care, and has seven 5-point Likert scale items that assess the extent to which the patient asked questions, offered opinions, and expressed concerns when meeting with the surgeon [35].

2) The BREAST-Q is a procedure-specific and validated PRO that measures $\mathrm{Hr}-\mathrm{QOL}$ and patient satisfaction with PMBR [36-39]. The "Satisfaction with Information" Subscale specifically measures patient satisfaction with the preoperative information and care provided by the plastic surgeon and other members of the medical team. There are 15 items that use a four-level Likert scale response format; the score is transformed on a scale of 0 to 100 with higher scores indicating greater satisfaction [36-39].

Service outcomes will be measured using the uptake rate of breast reconstruction, consultation length, number of consultations until a decision is made (consent signed), the physician satisfaction scale [40], and a breast reconstruction knowledge test [41].

\section{Baseline measures}

Patient demographic and clinical characteristics, baseline psychosocial measures such as the Spielberger StateTrait Anxiety Inventory (STAI) [42], a social support survey [43], and preference for decision control [44] will be captured on our routine two-page patient intake form after consent but prior to randomization and allocation (T0, Figure 1). Baseline covariates that will be documented include demographic variables, including age, marital status, ethnicity, household annual income, highest level of education, urban vs. nonurban place of residence, and employment status, and clinical covariates, including study site, timing of the reconstruction (immediate vs. delayed), previous stage of breast cancer, prior receipt of radiation, prior receipt of chemotherapy, and presence of chronic illness.

STAI is a 20-item measure of anxiety, and its scores range from 20-80, with a higher score indicating greater anxiety [42]. The STAI trait subscale will be measured at baseline, and the state subscale will be measured at baseline and T1. The state subscale is a sensitive indicator of changes in transitory anxiety in behavior modification programs or with experimental procedures.

The Medical Outcomes Study Social Support Survey has a series of 18 questions that measure four domains of social support (emotional, tangible, affectionate, and social interactions). Responses range from 1 (none of the time) to 5 (all the time). The items in each domain were summed and then transformed to yield scores ranging from 0 to 100. Higher scores indicate more support [43].

Preference for Decision Control is assessed using a validated question from previous studies in cancer patients where patients indicate whether they want to play an active, passive, or collaborative role with their physician when making a treatment decision [35].

\section{Analysis}

Analysis of primary and secondary outcomes from the main trial will be summarized using measures of central tendency and dispersion. This pilot study will provide important information regarding the treatment effect estimate and variability (standard deviation) to supplement 
what has been reported in observational studies and will be used to guide the design and sample size calculation for the main trial. Because this is a pilot study, we do not propose to undertake formal hypothesis tests of the primary or secondary endpoints for the definitive trial.

\section{Qualitative analysis}

Thematic analysis [45] will be used to extract emerging themes and variations. Concurrent data collection and analysis will be undertaken using multi-layered reading and constant comparison [46]. N-vivo 10.0 software will be used for data management. An audit trail, detailed field notes, and memos will be maintained throughout the research process.

\section{Sample size and power}

Sample size for the pilot study is determined based on the recommended sample size of approximately 40 participants for a pilot study [47]. Approximately 20 patients are referred for breast reconstruction per surgeon per month. Workshops and clinics have the capacity for five and ten patients per session, respectively. A conservative estimate of $50-70 \%$ recruitment would allow us to recruit our pilot sample size over 6 months across four clinics.

\section{Interpretation of pilot results}

Feasibility targets include $\geq 60 \%$ recruitment, $\geq 80 \%$ retention after randomized treatment assignment, and $\geq 80 \%$ completion of primary outcome measure. Success will also be measured based on high treatment fidelity measured through observation of the intervention and participant qualitative report. To inform our decision for the primary outcome for a definitive RCT, the most important outcome measure for patients will be solicited and ascertained through qualitative methods.

\section{Discussion}

To reduce unnecessary variation in treatment and improve quality of cancer care among breast cancer patients, there has been a growing interest in engaging patients through the decision-making process [48,49]. Particularly for breast reconstruction there is a paucity of studies designed to address patients' unique informational and supportive-care needs, and there has been a call to action to develop and implement interventions that enhance patient empowerment [50]. Only one RCT has designed and implemented a decision support intervention for patients considering breast reconstruction [51]. While patients assigned to the pre-consultation computer-based decision support intervention demonstrated greater knowledge scores, outcomes related to shared decision-making or decision quality were not assessed using validated instruments [51]. Retrospective observational studies from single institutions suggest that well-informed patients already participate in the decision whether or not to undergo breast reconstruction $[12,41]$, but interventions can improve involvement and satisfaction for the decision regarding the type of reconstruction (implant-based or autologous tissue reconstruction) among women who decided to have breast reconstruction [52]. However, inferences regarding the utility of decision-support interventions for breast reconstruction patients from non-randomized and particularly retrospective studies must be made with caution. Furthermore, no study has examined the potential of group workshops to enhance patient engagement and decision quality; educational interventions delivered in a group setting have been demonstrated to be an effective tool to address informational and psychosocial needs for breast cancer survivors [30]. Therefore, we designed a novel intervention to address identified gaps in care to promote shared decision-making and improve the quality of patient decisions surrounding breast reconstruction.

Because the intervention occurs before the initial surgical consultation (necessitating telephone recruitment) and is delivered using a novel format in a group setting, we felt it would be most appropriate to first undertake a pilot study prior to a definitive trial. Our pilot study seeks to identify (1) the feasibility, acceptability, and design of a definitive RCT and (2) the optimal content and delivery of our proposed educational group intervention. Results from our pilot study will be used in the following two ways: (1) to validate the design of the intervention and revise content and delivery to meet the needs of the end-users; (2) to inform the final design and sample size estimation for a definitive RCT.

\section{Trial status}

The pre-consultation educational group intervention pilot trial began recruitment in January 2013. Thirty patients have been recruited to date (18 May 2013), of whom 15 have been randomized to one of three decision support workshops. Once all participants have been recruited and enrolled, we will complete qualitative interviews among a purposeful sample of voluntary participants. Recruitment is ongoing, and the trial is scheduled to be completed by the end of this academic year (June 2013).

\section{Competing interests}

The authors declare they have no competing interests.

\section{Authors' contributions}

Conception and study design (TZ, JP, NB, JJ, NC, KM); recruitment of participants (TZ, SH, AO, NC); development and implementation of workshop (JP, TZ, NC, TC, ES, JJ, SH, AO); drafting of manuscript (JP, TZ); critical review of manuscript (all authors). All authors read and approved the final manuscript. 


\section{Acknowledgements}

Contributing surgeons include (in alphabetical order): Dr. Stefan OP Hofer, Dr. Anne O'Neill, and Dr. Toni Zhong. Contribution to data collection and study management: Catherine Butler and Natalie Causarano at the UHN. Contribution to delivery of Educational Workshops: Natalie Causarano, Terry Cheng, Jennica Platt, Elizabeth Starenkyj, Scott Secord, and the staff at the Electronic Living Lab for Interdisciplinary Cancer Survivorship Research. The investigators would like to thank all patients who participated in the study.

\section{Funding}

Dr. Platt is supported by research fellowships from the Canadian Breast Cancer Foundation-GlaxoSmithKline Physician Fellowship Program and the Canadian Institutes of Health Research. Dr. Zhong is supported by the Conquer Cancer Foundation Career Development Award from the American Society of Clinical Oncology. Dr. Baxter holds the Cancer Care Ontario Health Services Research Chair. Dr. Hofer is supported by the Wharton Chair in Plastic and Reconstructive Surgery from the University Health Network. Drs. Zhong, Hofer, and Metcalfe received grant funding from the Canadian Breast Cancer Foundation and the Canadian Institutes of Health Research.

\section{Research support}

This research was supported by the Physician Services Incorporated Foundation-Resident Grant awarded to Dr. Jennica Platt under the supervision of Dr. Toni Zhong. The opinions reported in this article are those of the authors and are independent from the funding source.

Received: 18 May 2013 Accepted: 26 June 2013

Published: 6 July 2013

\section{References}

1. Rowland JH, Aziz N, Tesauro G, Feuer EJ: The changing face of cancer survivorship. Semin Oncol Nurs 2001, 17(4):236-240.

2. Canadian Cancer Society's Steering Committee on Cancer Statistics. Canadian Cancer Statistics: Canadian Cancer Society. 2011. Available at: http://www.cancer.ca/Canada-wide/About-cancer/ /media/CCS/ Canadawide/Files-List/English-files-heading/PDF - Policy - Canadian Cancer Statistics - English/Canadian Cancer Statistics 2011 - English.ashx. Accessed Oct. 29, 2011.

3. Habermann EB, Abbott A, Parsons HM, Virnig BA, Al-Refaie WB, Tuttle TM: Are mastectomy rates really increasing in the United States? J Clin Oncol 2010, 28(21):3437-3441.

4. Cordeiro PG: Breast reconstruction after surgery for breast cancer. N Engl J Med 2008, 359(15):1590-1601

5. Zhong TC M, Min S, et al: Satisfaction and health-related quality of life following autologous tissue breast reconstruction: a prospective analysis of early postoperative outcomes. Cancer.

6. Potter S, Winters ZE: Does breast reconstruction improve quality of life for women facing mastectomy? A systematic review. Eur J Surg Oncol 2008, 34:1181. Abstract P1163.

7. Elder EE, Brandberg Y, Bjorklund T, et al: Quality of life and patient satisfaction in breast cancer patients after immediate breast reconstruction: a prospective study. Breast 2005, 14(3):201-208.

8. Wilkins EG, Cederna PS, Lowery JC, et al: Prospective analysis of psychosocial outcomes in breast reconstruction: one-year postoperative results from the Michigan Breast Reconstruction Outcome Study. Plast Reconstr Surg 2000, 106(5):1014-1025. discussion 1026-1017.

9. Yueh JH, Slavin SA, Adesiyun T, et al: Patient satisfaction in postmastectomy breast reconstruction: a comparative evaluation of DIEP, TRAM, latissimus flap, and implant techniques. Plast Reconstr Surg 2010, 125(6):1585-1595.

10. Cordeiro PG, McCarthy CM: A single surgeon's 12-year experience with tissue expander/implant breast reconstruction: part II. An analysis of long-term complications, aesthetic outcomes, and patient satisfaction. Plast Reconstr Surg 2006, 118(4):832-839.

11. Hu ES, Pusic AL, Waljee JF, et al: Patient-reported aesthetic satisfaction with breast reconstruction during the long-term survivorship period. Plast Reconstr Surg 2009, 124(1):1-8.

12. Lantz PM, Janz NK, Fagerlin A, et al: Satisfaction with surgery outcomes and the decision process in a population-based sample of women with breast cancer. Health Serv Res 2005, 40(3):745-767.
13. Coulter $\mathrm{A}$ : Patient information and shared decision-making in cancer care. Br J Cancer 2003, 89(Suppl 1):S15-S16.

14. Lee CN, Hultman CS, Sepucha K: Do patients and providers agree about the most important facts and goals for breast reconstruction decisions? Ann Plast Surg 2010, 64(5):563-566.

15. Spector D, Mayer DK, Knafl K, Pusic A: Not what I expected: informational needs of women undergoing breast surgery. Plast Sur Nurs 2010, 30(2):70-74. quiz 75-76.

16. Nissen MJ, Swenson KK, Kind EA: Quality of life after postmastectomy breast reconstruction. Oncol Nurs Forum 2002, 29(3):547-553.

17. Fernandes-Taylor S, Bloom JR: Post-treatment regret among young breast cancer survivors. Psychooncology 2011, 20(5):506-516.

18. Hack TF, Degner LF, Watson P, Sinha L: Do patients benefit from participating in medical decision making? Longitudinal follow-up of women with breast cancer. Psychooncology 2006, 15(1):9-19.

19. Sheehan J, Sherman KA, Lam T, Boyages J: Association of information satisfaction, psychological distress and monitoring coping style with post-decision regret following breast reconstruction. Psychooncology 2007, 16(4):342-351.

20. Wennberg JE, Fisher ES, Skinner JS: Geography and the debate over medicare reform. Health Aff 2002

21. O'Connor Annette M: User manual - decision self-efficacy scale [document on the internet]. 1995 [modified 2002]. Ottawa Hospital Research Institute. Available at: http://decisionaid.ohri.ca/docs/develop/user_manuals/ UM_decision_selfefficacy.pdf. Accessed Jan 21, 2012.

22. Hacking B, Wallace L, Scott S, Kosmala-Anderson J, Belkora J, McNeill A Testing the feasibility, acceptability and effectiveness of a 'decision navigation' intervention for early stage prostate cancer patients in Scotland - a randomised controlled trial. Psychooncology 2012. May 9.

23. Platt J, Baxter N, Zhong T: Breast reconstruction after mastectomy for breast cancer. CMAJ Canadian Med Assoc J 2011, 183(18):2109-2116.

24. Charles C, Gafni A, Whelan T: Decision-making in the physician-patient encounter: revisiting the shared treatment decision-making model. Soc Sci Med 1999, 49(5):651-661.

25. O'Connor Annette M: Ottawa Decision Support Framework to address decisional conflict. 2006. http://www.ohri.ca/decisionaid. Accessed Oct. 29, 2011.

26. Stacey D, Bennett Carol L, Barry Michael J, et al: Decision aids for people facing health treatment or screening decisions. Cochrane Database Syst Rev 2011(10). http://www.mrw.interscience.wiley.com/cochrane/clsysrev/ articles/CD001431/frame.html.

27. O'Connor Annette M, Llewellyn-Thomas H, Stacey DH: International Patient Decision Aid Standards Collaboration: Background Document. 2005. http://ipdas.ohri.ca/IPDAS_Background.pdf.

28. Fitch M: Supportive care for cancer patients. Hosp Q 2000, 3(4):39-46.

29. Adamsen L, Rasmussen JM: Sociological perspectives on self-help groups: reflections on conceptualization and social processes. J Adv Nurs 2001, 35(6):909-917.

30. Jones JM, Cheng T, Jackman M, et al: Getting back on track: evaluation of a brief group psychoeducation intervention for women completing primary treatment for breast cancer. Psychooncology 2011. Sep 9

31. Guest G, Bunce A, Johnson L: How many interviews are enough? An experiment with data saturation and variability. Field Methods 2006, 18(1):59-82.

32. O'Connor Annette M: User Manual - Decision Conflict Scale (16 item statement format) [document on the Internet]. Ottawa Hospital Research Institute; 1993. Available at: http://decisionaid.ohri.ca/docs/develop/ User_Manuals/UM_Decisional_Conflict.pdf. Accessed; cited 2011.11.10.

33. O'Connor Annette M: User Manual - Measures of Decision/Choice Predisposition [document on the Internet]. Ottawa Hospital Research Insitute; 1996. Available at: http://decisionaid.ohri.ca/docs/develop/User_Manuals/ UM_ChoicePredisposition_Decision.pdf. Accessed 03 OCTOBER, 2012.

34. McCaffery K, Irwig L, Bossuyt P: Patient decision aids to support clinical decision making: evaluating the decision or the outcomes of the decision. Med Decis Making 2007, 27(5):619-625.

35. Lerman CE, Brody DS, Caputo GC, Smith DG, Lazaro CG, Wolfson HG: Patients' perceived involvement in care scale: relationship to attitudes about illness and medical care. J Gen Intern Med 1990, 5:29-33.

36. Klassen AF, Pusic AL, Scott A, Klok J, Cano SJ: Satisfaction and quality of life in women who undergo breast surgery: a qualitative study. BMC Womens Health 2009, 9:11. 
37. Pusic AL, Klassen AF, Scott AM, Klok JA, Cordeiro PG, Cano SJ: Development of a new patient-reported outcome measure for breast surgery: the BREAST-Q. Plast Reconstr Surg 2009, 124(2):345-353.

38. Scientific Advisory Committee of the Medical Outcomes Trust: Assessing health status and quality of life instruments: attributes and review criteria. Qual Life Res 2002, 11:193-205.

39. U.S. Food and Drug Administration: Patient reported outcome measures: Use in medical product development to support labelling claims. 2006.

40. Sepucha K, Belkora J, Mutchnick S, Esserman L: Consultation planning to help breast cancer patients prepare for medical consultations: effect on communication and satisfaction for patients and physicians. J Clin Oncol 2002, 20(11):2695-2700.

41. Lee CN, Belkora J, Chang Y, Moy B, Partridge A, Sepucha K: Are patients making high-quality decisions about breast reconstruction after mastectomy? [outcomes article]. Plast Reconstr Surg 2011, 127(1):18-26.

42. Spielberger CD, Gorsuch RL, Lushene R, Vagg PR, Jacobs GA: Manual for the State-Trait Anxiety Inventory. Palo Alto, CA: Consulting Psychologists Press; 1983.

43. Sherbourne CD, Stewart AL: The MOS social support survey. Soc Sci Med 1991, 32(6):705-714.

44. Degner LF, Kristjanson $L$, Bowman D, et al: Information needs and decisional preferences in women with breast cancer. JAMA 1997, 277(18):1485-1492.

45. Creswell JW: Qualitative Inquiry and Research Design. Thousand Oaks, CA: Sage Publications; 1998.

46. Straus A, Corbin J: Basics of Qualitative Research. 2nd edition. Thousand Oaks, CA: Sage Publications; 1998.

47. Hertzog MA: Considerations in determining sample size for pilot studies. Res Nurs Health 2008, 31(2):180-191.

48. Waljee JF, Rogers MA, Alderman AK: Decision aids and breast cancer: do they influence choice for surgery and knowledge of treatment options? J Clin Oncol 2007, 25(9):1067-1073.

49. Sepucha KR, Fowler FJ Jr, Mulley AG Jr: Policy support for patient-centered care: the need for measurable improvements in decision quality. Health Aff (Millwood) 2004. Suppl Variation: VAR54-62.

50. Preminger BA, Lemaine V, Sulimanoff I, Pusic AL, McCarthy CM: Preoperative patient education for breast reconstruction: a systematic review of the literature. $J$ Cancer Educ 2011, 26(2):270-276.

51. Heller L, Parker PA, Youssef A, Miller MJ: Interactive digital education aid in breast reconstruction. Plast Reconstr Surg 2008, 122(3):717-724.

52. Lee BT, Chen C, Yueh JH, Nguyen M-D, Lin SJ, Tobias AM: Computer-based learning module increases shared decision making in breast reconstruction. Ann Surg Oncol 2009, 17(3):738-743.

doi:10.1186/1745-6215-14-199

Cite this article as: Platt et al.: Pre-consultation educational group intervention to improve shared decision-making in postmastectomy breast reconstruction: study protocol for a pilot randomized controlled trial. Trials 2013 14:199.

\section{Submit your next manuscript to BioMed Central and take full advantage of:}

- Convenient online submission

- Thorough peer review

- No space constraints or color figure charges

- Immediate publication on acceptance

- Inclusion in PubMed, CAS, Scopus and Google Scholar

- Research which is freely available for redistribution 